\title{
A Modern Approach to Analyzing the Flowing Pressures of a Two-Phase CBM and Water Column in Producing Wellbores
}

\author{
Xinfu Liu $\left(\mathbb{D},{ }^{1}\right.$ Chunhua Liu $\left(\mathbb{D},{ }^{2}\right.$ and Jianjun $\mathrm{Wu}^{3}$ \\ ${ }^{1}$ School of Mechanical and Automotive Engineering, Qingdao University of Technology, Qingdao, 266520 Shandong, China \\ ${ }^{2}$ College of Mechanical and Electronic Engineering, China University of Petroleum (East China), Qingdao, 266580 Shandong, China \\ ${ }^{3}$ PetroChina Coalbed Methane Co. Ltd., Xi'an, 710082 Shanxi, China
}

Correspondence should be addressed to Xinfu Liu; upcdoctor@126.com and Chunhua Liu; 20090053@upc.edu.cn

Received 25 September 2018; Accepted 13 March 2019; Published 7 May 2019

Academic Editor: Andri Stefansson

Copyright (C) 2019 Xinfu Liu et al. This is an open access article distributed under the Creative Commons Attribution License, which permits unrestricted use, distribution, and reproduction in any medium, provided the original work is properly cited.

A modern methodology is presented for the system analysis of flowing pressures in order to forecast the dynamic behavior and solve the forthcoming problems that emerge in two-phase coalbed methane (CBM) wellbores. The proposed methodology involves a numerical integration technique to calculate flowing pressures and pressure drops of CBM and water flow from the bottom hole to the well head. The methodology is validated against full-scale measured data in coalfields. The relationships developed match CBM reservoir behavior and wellbore conditions along the annulus with an overall accuracy of $1.13 \%$. The computation of flowing pressures involves a liquid holdup and kinetic energy term with flow rate increments, a compressibility factor with depth increments, and a friction factor with Reynolds number. The flowing pressures of a two-phase column fully reflect the dynamic flowing performance due to the combined action of the water level, CBM, and water flow rates. The effect of $\mathrm{CBM}$ and water column pressures is more obvious than that of CBM column pressures. The pressure ratios of CBM and the water column to the bottom hole decline rapidly with the increase of the dynamic water level. CBM and water flow rates can be improved with increases in CBM and water column pressure for two-phase producing wellbores. The decrease of flowing pressures and increased increment of the pressure drop for the two-phase column are beneficial to CBM desorption and result in the increased CBM and water production. It will control the falling speed of the dynamic water level above CBM and the water column and enhance CBM reservoir productivity. The increases of CBM and water column pressure from $34.6 \mathrm{kPa}$ to $922 \mathrm{kPa}$ and the decreases of pressure in the bottom hole from $2.252 \mathrm{MPa}$ to $1.328 \mathrm{MPa}$ lead to the increases of the CBM flow rate from $3327 \mathrm{~m}^{3} / \mathrm{d}$ to $6721 \mathrm{~m}^{3} / \mathrm{d}$.

\section{Introduction}

Periodic analysis of flowing pressures can forecast the dynamic behavior in CBM reservoirs and solve the common problems that emerge in two-phase producing wellbores $[1,2]$. A reliable and accurate approach to predicting flowing pressures is essential to design artificial lifting systems and optimize production performance for the given two-phase CBM well $[3,4]$. An alternative approach is to equip the CBM wellbores with pressure gauges and finish actual measurement of flowing pressures along the annulus. But it is a costly operation for the whole CBM production. Another methodology is to estimate the flowing pressures and pressure drops in two-phase producing wellbores with respect to the well liquids and well datum.

Obeida and Mosallam and Rendeiro and Kelso $[5,6]$ recommended the Average Pressure and Temperature method. This methodology was developed with the solution of the general mechanical energy balance for a conventional gas well. And the variation of the $Z$-factor could be accounted for by assuming the single-phase gas well to be at an average pressure and temperature throughout the entire wellbore. However, this procedure does not perform well for most deep, high-temperature, and high-pressure gas wells. When such gas wells produce at low gas/liquid ratios, this method is even less reliable. Cullender and Smith (see $[7,8]$ ) 
proposed a more practical methodology for calculating the flowing pressures and pressure drops in conventional gas wells that produce liquids. And it takes the variations in temperature and gas compressibility with depth into account. But the Cullender and Smith methodology was developed for the single-phase well with gas occupying the wellbore. And the absolute roughness of the rough-turbulent flow is $6.0 \times 10^{-4}$ inches in dry-gas wells. Mohammadpoor et al. and Osman and Aggour [9, 10] proposed Artificial Neural Networks (ANN) which are parallel-distributed information processing models. ANN has been applied to resolve multiphase flow problems and achieved promising results compared with correlations and mechanistic models. However, it is not possible to confirm the complexity of the model as the individual testing errors were not reported and the models of ANN were not evaluated with independent data sets.

These relationships generally modified and applied various simplified assumptions and a theoretical analytic approach or just developed approximate computational formulae of conventional gas fields and dry-gas wells to calculate the flowing pressures and pressure drops. Therefore, these modeling procedures, if applied to the CBM wellbores that produce water, could not help one to identify the specific phenomena that occur during the two-phase pumping production and do not give the desired results to predict the flowing performance along the annulus. The main reason is that differences exist between coal geology and gas formations $[11,12]$, including low water production, high dynamic water level, short stroke, and the pumping speed dropping down rapidly.

In order to predict the dynamic behavior of the twophase flow in producing CBM wellbores and provide the reliable basis for the design of artificial lifting systems, the methodology was proposed to calculate the flowing pressures and pressure drops along the annulus. The mathematical models of flowing performance for two-phase CBM and water flow were developed, and the accurate flowing pressures were predicted due to the specific CBM wellbore conditions along the annulus stretching over a wider range.

\section{Model Development of CBM Flow}

Based on the characteristics of CBM and the water flow in coal reservoirs, the complete producing process can be divided into four phases including the pumping prophase, single-phase water flow, two-phase (CBM plus water) flow, and single-phase CBM flow [13-15]. Some CBM saturation is likely to develop near the wellbore, if the CBM well is drawn down enough to cause desorption in the near wellbore area. The coal reservoirs will exhibit two-phase flowing performances while the CBM wellbore has reached the boundary-dominated flow [16-18]. Then, the coal reservoirs will produce less and less water while the CBM flow rate enhances gradually until its peak is reached.

The proposed methodology involves a numerical integration technique to calculate CBM column pressures, based on the gas flow equation and well flowing model. And the methodology would provide accurate results while it takes the variations of CBM temperature and compressibility factor with gravitational gradients and friction factor with velocity into account. Considering the CBM column flow from the dynamic water level to the well head along the annulus between the tubing and casing, the energy balance $[19,20]$ for the computation of CBM column pressure in two-phase CBM wellbores can be modified as follows:

$$
\frac{\mathrm{d} p}{\mathrm{~d} h}+3.419 \times 10^{4} \gamma_{\mathrm{c}} \frac{p}{Z T}+4.520 \times 10^{-8} \frac{\gamma_{\mathrm{c}} f}{d^{5}} \frac{Z T}{p} q_{\mathrm{sc}}^{2}=0
$$

where $d$ is the diameter of the CBM column in $\mathrm{m}, f$ is the friction factor, $h$ is the coordinate of the depth in $\mathrm{m}, p$ is the pressure of the CBM column in $\mathrm{Pa}, q_{\mathrm{sc}}$ is the CBM flow rate in $\mathrm{m}^{3} / \mathrm{d}, T$ is the temperature of the wellbore in $\mathrm{K}, Z$ is the CBM compressibility factor, and $\gamma_{\mathrm{c}}$ is CBM specific gravity.

The estimation of CBM column pressures involves calculating the energy losses of friction resistance and the hydrostatic head in the CBM wellbore. Upon transformation of the variable and integration, the energy equation can be simplified to the following pressure formula:

$$
\begin{aligned}
& 3.42 \times 10^{-2} \gamma_{\mathrm{c}} h_{\mathrm{c}} \\
& =\int_{P_{\mathrm{hf}}}^{P_{\mathrm{tcf}}} \frac{Z p T}{p^{2}+\left(\left(1.322 \times 10^{-18} Z^{2} f q_{\mathrm{sc}}^{2} T^{2}\right) /\left(\left(d_{\mathrm{t}}+d_{\mathrm{c}}\right)^{2}\left(d_{\mathrm{c}}-d_{\mathrm{t}}\right)^{3}\right)\right)} \mathrm{d} p,
\end{aligned}
$$

where $d_{\mathrm{c}}$ is the inside diameter of the casing in $\mathrm{m}, d_{\mathrm{t}}$ is the outside diameter of the tubing in $\mathrm{m}, h_{\mathrm{c}}$ is the depth of the CBM column in $m, p_{\text {hf }}$ is the flowing pressure near the well head in $\mathrm{MPa}$, and $p_{\mathrm{tcf}}$ is the flowing pressure on the dynamic water level in two-phase CBM wellbores in $\mathrm{MPa}$.

The CBM compressibility factor, $Z$, is known as a function of pseudoreduced density, $\rho_{\mathrm{pr}}$, and pseudoreduced temperature, $T_{\text {pr }}$, for the CBM column. An explicit factor, which is an accurate mathematical approximation [21, 22], is developed due to experimental results and given by

$$
Z=\frac{0.299-2.188 \times 10^{-2} \gamma_{\mathrm{c}}-4.698 \times 10^{-3} \gamma_{\mathrm{c}}^{2}}{\rho_{\mathrm{pr}} T_{\mathrm{pr}}} \exp \left[-12\left(\frac{T_{\mathrm{pr}}-1}{T_{\mathrm{pr}}}\right)^{2}\right] .
$$

Since the friction losses cannot be measured directly, the correlation is used to determine the friction factor $[23,24]$. This factor is a function of both relative roughness in the wellbore and the Reynolds number [23, 24] of the CBM column. Relative roughness in the wellbore is usually described in terms of the ratio of absolute roughness, $e$, to the annulus diameter $\left(d_{\mathrm{c}}-d_{\mathrm{t}}\right)$. This corresponds to the absolute roughness of the annulus in CBM wellbores and has been proved to be experimentally correct for different test CBM columns based on the laboratory investigation. Therefore, an explicit correlation for the friction factor of the CBM column in the wellbores 
is developed and can be found from the formula given as follows:

$f^{-0.5}=1.14-21 g\left\{\frac{e}{d_{\mathrm{c}}-d_{\mathrm{t}}}+3.21 \times 10^{-5}\left[\frac{\mu_{\mathrm{c}}}{q_{\mathrm{sc}} \gamma_{\mathrm{c}}}\left(d_{\mathrm{t}}+d_{\mathrm{c}}\right)\right]^{0.88}\right\}$,

where $\mu_{\mathrm{c}}$ is the viscosity of the CBM column in $\mathrm{mPa} \cdot \mathrm{s}$.

The integrand of the pressure drop, $I$, is introduced in order to simplify the iterative calculations, and it is defined as follows:

$$
I=\frac{p / Z T}{(p / Z T)^{2}+1.32 \times 10^{-18}\left(q_{\mathrm{sc}}^{2} f /\left(\left(d_{\mathrm{c}}-d_{\mathrm{t}}\right) \cdot\left(d_{\mathrm{c}}^{2}-d_{\mathrm{t}}^{2}\right)^{2}\right)\right)} .
$$

The mathematical model of flowing pressures for the CBM column is solved with numerical integration due to the numeric analysis. And the procedure involves iterative calculations with regard to two parts of the CBM column above the dynamic water level in producing wellbores. The flowing pressure for the middle part of the whole CBM column, $p_{\mathrm{mf}}$, can be determined due to the measurements of pressure near the well head. And then, the equation for the upper CBM column pressure can be given by

$$
3.42 \times 10^{-2} \gamma_{\mathrm{c}} h_{\mathrm{c}}=\left(p_{\mathrm{mf}}-p_{\mathrm{hf}}\right)\left(I_{\mathrm{mf}}+I_{\mathrm{hf}}\right) .
$$

The flowing pressure, $p_{\mathrm{tcf}}$, can be determined based on the results of the pressure for the middle part of the whole CBM column in producing wellbores. And then, the equation for the lower CBM column pressure can be determined as follows:

$$
p_{\mathrm{tcf}}=p_{\mathrm{hf}}+0.205 \frac{\gamma_{\mathrm{c}} h_{\mathrm{c}}}{I_{\mathrm{hf}}+4 I_{\mathrm{mf}}+I_{\mathrm{tcf}}} .
$$

The mathematical model can be solved for the upper and lower CBM column pressures as follows:

(1) Calculate the integrand $I_{\mathrm{hf}}$ or $I_{\mathrm{mf}}$ and the product of $\gamma_{\mathrm{c}}$ and $h_{\mathrm{c}}$ by using the well head and wellbore measurements in producing CBM wellbores

(2) Complete the initial computation with the help of the integrand $I_{\mathrm{mf}}$ equal to $I_{\mathrm{hf}}$ or the integrand $I_{\mathrm{tcf}}$ equal to $I_{\mathrm{mf}}$

(3) Determine the flowing pressure, $p_{\mathrm{mf}}$ or $p_{\mathrm{tcf}}$, and the integrand, $I_{\mathrm{mf}}$ or $I_{\mathrm{tcf}}$, for the upper and lower CBM column in producing wellbores

(4) Iterate by returning to step 3 until the accurate result of $p_{\mathrm{mf}}$ or $p_{\mathrm{tcf}}$ is obtained

The flowing pressure on the dynamic water level of twophase CBM wellbores, $p_{\text {tcf }}$, can be iterated as the sum of the pressure near the well head and CBM column pressure.
Repeat the above procedure until the desired accuracy of $p_{\text {tcf }}$ is obtained.

\section{Model Development of CBM and Water Flow}

The proposed methodology involves a numerical integration technique to calculate CBM and water column pressure and flowing pressure in the bottom hole of two-phase producing wellbores. And this mathematical model is developed based on the energy balance for the computation of the flowing pressures about the multiphase column $[25,26]$. And it takes the compressibility factor with gravitational gradients, friction factor with the two-phase Reynolds number, and liquid holdup with the flow rate into account.

For the CBM and water flow wellbores, the energy balance equation can be modified to include the two-phase (CBM and water) flow [27, 28]. The following energy balance equation for the computation of CBM and water column pressure can be expressed as follows:

$$
\mathrm{d} p=\rho_{\mathrm{t}} g \mathrm{~d} h+\rho_{\mathrm{t}} v_{\mathrm{t}} \mathrm{d} v_{\mathrm{t}}-\frac{0.5 \rho_{\mathrm{t}} f_{\mathrm{t}}}{d_{\mathrm{c}}-d_{\mathrm{t}}} v_{\mathrm{t}}^{2} \mathrm{~d} h,
$$

where $f_{\mathrm{t}}$ is the CBM-water friction factor, $v_{\mathrm{t}}$ is the flowing velocity of CBM plus water in $\mathrm{m} / \mathrm{s}$, and $\rho_{\mathrm{t}}$ is the mixture density of CBM plus water $[29,30] \mathrm{in} \mathrm{kg} / \mathrm{m}^{3}$.

Two parameters are introduced to calculate CBM and water column pressures. They are mixture density, $\rho_{\mathrm{t}}$, and flowing velocity of CBM plus water, $v_{\mathrm{t}}$.

$$
\begin{aligned}
& \rho_{\mathrm{t}}=\rho_{\mathrm{c}}\left(1-H_{\mathrm{l}}\right)+\rho_{\mathrm{w}} H_{\mathrm{l}}, \\
& v_{\mathrm{t}}=1.47 \times 10^{-5}\left[\frac{H_{\mathrm{l}} B_{\mathrm{w}}}{d_{\mathrm{c}}^{2}-d_{\mathrm{t}}^{2}} q_{\mathrm{w}}+\frac{\left(1-H_{\mathrm{l}}\right) B_{\mathrm{c}}}{d_{\mathrm{c}}^{2}-d_{\mathrm{t}}^{2}} q_{\mathrm{sc}}\right], \\
& B_{\mathrm{c}}=3.46 \times 10^{-4} \frac{Z T}{p} .
\end{aligned}
$$

The premise that high flowing annular velocities in producing wellbores can cause CBM-water liquid holdup [31-33] in the annulus between the tubing and casing is presented. Then, a case is made that the annular cross-sectional area is inadequate to allow CBM-water separation to occur, preventing well liquid from falling below the turbulent perforations to the sucker rod pump intake. Extensive theoretical and experimental research is conducted on vertical, inclined, and horizontal gas-water flow. The data for experimental research cover CBM-water liquid holdups between 0 and 0.50 , and the CBM flow can be changed from a continuous process to an intermittent process in order to solve CBMwater separation problems in two-phase producing wellbores. CBM-water liquid holdup $H_{1}$ at the well head can be found to be correlative with superficial velocities of CBM and water, and its function is given by

$$
H_{1}=\frac{4.18 B_{\mathrm{w}} q_{\mathrm{w}}}{4.18 B_{\mathrm{w}} q_{\mathrm{w}}+B_{\mathrm{c}} q_{\mathrm{sc}}},
$$


where $B_{\mathrm{c}}$ is the formation volume factor of CBM, $B_{\mathrm{w}}$ is the formation volume factor of water, $H_{1}$ is CBM-water liquid holdup, $q_{\mathrm{w}}$ is the water flow rate in $\mathrm{m}^{3} / \mathrm{d}, \rho_{\mathrm{c}}$ is the density of the CBM column in $\mathrm{kg} / \mathrm{m}^{3}$, and $\rho_{\mathrm{w}}$ is the density of the water column in $\mathrm{kg} / \mathrm{m}^{3}$.

Based on the integration, the energy balance equation for the computation of CBM and water column pressure can be modified to the following equation:

$$
\begin{aligned}
\mathrm{d} p=10^{-6} \frac{\rho_{\mathrm{t}}}{2} \mathrm{~d} v_{\mathrm{t}}^{2}+10^{-6} \rho_{\mathrm{t}} g \mathrm{~d} h+1.086 \\
\times 10^{-16} \frac{f_{\mathrm{t}} \rho_{\mathrm{t}}\left[H_{\mathrm{l}} B_{\mathrm{w}} q_{\mathrm{L}}+\left(1-H_{\mathrm{l}}\right) B_{\mathrm{c}} q_{\mathrm{sc}}\right]^{2}}{\left(d_{\mathrm{c}}-d_{\mathrm{t}}\right)\left(d_{\mathrm{c}}^{2}-d_{\mathrm{t}}^{2}\right)^{2}} \mathrm{~d} h, \\
\rho_{\mathrm{t}}=H_{\mathrm{l}} \rho_{\mathrm{w}}+3.48 \times 10^{3}\left(1-H_{\mathrm{l}}\right) \frac{\gamma_{\mathrm{c}}}{Z} \frac{p}{T} .
\end{aligned}
$$

An explicit correlation for CBM-water friction factor $f_{\mathrm{t}}$ corresponds to the relative roughness in the annulus between the tubing and casing. The CBM-water friction factor is obtained with the help of experimental data about pressure drops of CBM and the water column in different test twophase flow columns. This factor is also a function of relative roughness in the wellbore and CBM-water Reynolds number and can be evaluated from the formula given as follows:

$$
\frac{1}{\sqrt{f_{\mathrm{t}}}}=1.14-21 g\left(\frac{e}{d_{\mathrm{c}}-d_{\mathrm{t}}}+\frac{21.25}{\operatorname{Re}_{\mathrm{t}}^{0.90}}\right) \text {. }
$$

The CBM-water Reynolds number $\left(\mathrm{Re}_{t}\right)$ is determined in terms of flowing velocity, mixture density, and flowing viscosity of CBM and the water column.

$$
\operatorname{Re}_{\mathrm{t}}=\frac{v_{\mathrm{t}} d\left(\rho_{\mathrm{w}} q_{\mathrm{w}}+\rho_{\mathrm{c}} q_{\mathrm{sc}}\right)}{\mu_{\mathrm{w}}^{H_{1}} \mu_{\mathrm{c}}^{\left(1-H_{\mathrm{l}}\right)}\left(q_{\mathrm{w}}+q_{\mathrm{sc}}\right)}
$$

Since Newtonian viscous force is related to the lubrication perimeter, the CBM-water Reynolds number in the annulus between the tubing and casing can be calculated as follows:

$\operatorname{Re}_{\mathrm{t}}=1.47 \times 10^{-2} \frac{\left(d_{\mathrm{c}}+d_{\mathrm{t}}\right)\left(\rho_{\mathrm{w}} q_{\mathrm{w}}+\rho_{\mathrm{c}} q_{\mathrm{sc}}\right)\left[H_{\mathrm{l}} B_{\mathrm{w}} q_{\mathrm{w}}+\left(1-H_{1}\right) B_{\mathrm{c}} q_{\mathrm{sc}}\right]}{\mu_{\mathrm{w}}^{H_{1}} \mu_{\mathrm{c}}^{\left(1-H_{1}\right)}\left(q_{\mathrm{w}}+q_{\mathrm{sc}}\right)\left(d_{\mathrm{c}}^{2}-d_{\mathrm{t}}^{2}\right)}$,

where $\mu_{\mathrm{w}}$ is the flowing viscosity of the water column in $\mathrm{mPa} \cdot \mathrm{s}$.

The kinetic energy term, $\Delta v_{\mathrm{t}}^{2}$, can be determined as the difference of flowing velocity of CBM and the water column $v_{\mathrm{t}, j}$ at $p_{j}$ and $T_{j}$ and $v_{\mathrm{t}, j-1}$ at $p_{j-1}$ and $T_{j-1}$. And the formula of the kinetic energy term can be expressed as follows:

$$
\Delta v_{\mathrm{t}}^{2}=1.62\left(\frac{q_{\mathrm{w}, j}+q_{\mathrm{sc}, j}}{d_{\mathrm{c}}^{2}-d_{\mathrm{t}}^{2}}\right)^{2}-1.62\left(\frac{q_{\mathrm{w}, j-1}+q_{\mathrm{sc}, j-1}}{d_{\mathrm{c}}^{2}-d_{\mathrm{t}}^{2}}\right)^{2} .
$$

The depth of the two-phase flow column from the dynamic water level to the middle of the coal reservoir is numerically implemented into several computer programs.
And it can simulate the coupled flow of CBM and water in producing CBM wellbores. The depth of each increment, $\Delta h$, is equal and can be regarded as a function of the ratio between the depth of the two-phase flow column, $h_{\mathrm{t}}$, and the number of moles. Therefore, the depth ratio of each increment to the whole two-phase flow column should be selected as low as possible in order that the accurate results can be obtained. Based on the iterative analysis, the incremental pressure of CBM and the water column, $\Delta p_{\mathrm{t}}$, can be determined due to the measurements of pressure in two-phase flow wellbores and the results of pressure on the dynamic water level as follows:

$$
\begin{aligned}
\frac{\Delta p_{\mathrm{t}, j}}{\Delta h}= & 5.0 \times 10^{-7} \rho_{\mathrm{t}} \frac{\Delta v_{\mathrm{t}, j}^{2}}{\Delta h}+10^{-6} \rho_{\mathrm{t}} g \\
& -1.09 \times 10^{-16} \frac{f_{\mathrm{t}} \rho_{\mathrm{t}}\left[H_{\mathrm{l}} B_{\mathrm{w}} q_{\mathrm{w}}+\left(1-H_{\mathrm{l}}\right) B_{\mathrm{c}} q_{\mathrm{sc}}\right]^{2}}{\left(d_{\mathrm{c}}-d_{\mathrm{t}}\right)\left(d_{\mathrm{c}}^{2}-d_{\mathrm{t}}^{2}\right)^{2}} .
\end{aligned}
$$

The above procedure involves the iterative computations by dividing the two-phase flow column into several increments. And then, the mathematical model can be solved for CBM and water column pressure as follows:

(1) Determine the pseudoreduced density, $\rho_{\mathrm{pr}, j}$, and pseudoreduced temperature, $T_{\mathrm{pr}, j}$, yielding $Z_{j}$ by solving equation (3)

(2) Determine formation volume factors $B_{\mathrm{c}}$ and $B_{\mathrm{w}}$ for the value of CBM-water liquid holdup $H_{1}$ and calculate $\mathrm{Re}_{\mathrm{t}}$ for the value of CBM-water friction factor $f_{\mathrm{t}}$

(3) Solve equation (15) and equation (16) for the incremental pressure of CBM and water column, $\Delta p_{\mathrm{t}, j}$

(4) Iterate by returning to Step 1 until the accurate result of $\Delta p_{\mathrm{t}, j}$ is obtained

(5) Update $p_{j+1}=p_{j}+\Delta p_{\mathrm{t}, j+1}$ and repeat the above procedure until the desired accuracy of $p_{n}$ is obtained. In the iterative computation, the incremental pressures $p_{0}$ and $p_{n}$ are defined as the flowing pressure on the dynamic water level, $p_{\text {tcf }}$, and bottom hole pressure in the bottom hole, $p_{\mathrm{bf}}$, in two-phase CBM wellbores, respectively

As shown in Figure 1, flowing pressures in the bottom hole resulted from the combined action of the abovementioned pressures for the two-phase flow in CBM wellbores producing water. The CBM column flows upward while the water column flows downward in two-phase producing wellbores. And, hence, the CBM column pressure and CBM and water column pressure can be found by the CBM and twophase flow formulae. Consequently, the flowing pressure in the bottom hole, $p_{\mathrm{bf}}$, can be iterated as the sum of the pressure near the well head, $p_{\mathrm{hf}}, \mathrm{CBM}$ column pressure, $\Delta p_{\mathrm{c}}$, and CBM and water column pressure, $\Delta p_{\mathrm{t}}$, in two-phase producing wellbores. 


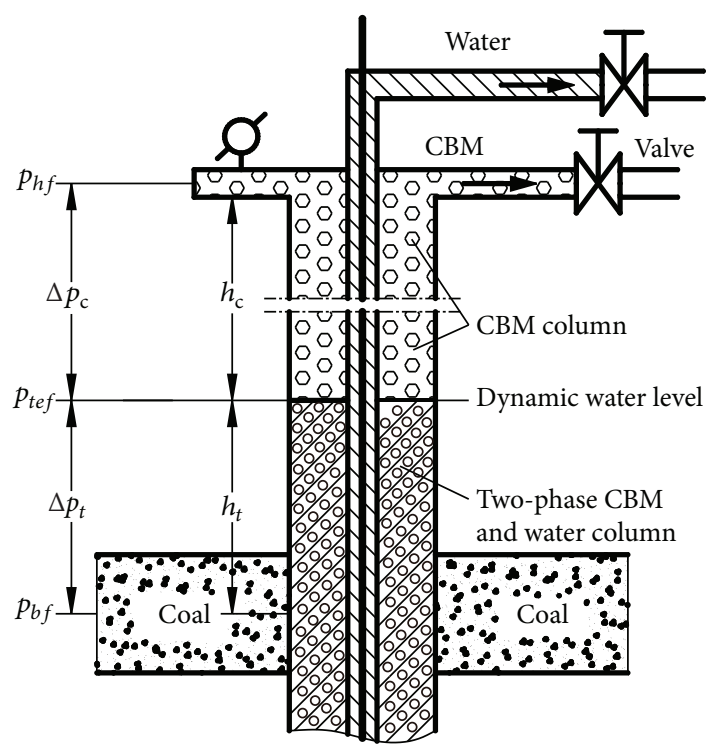

FIGURE 1: The components of flowing pressures and pressure drops in two-phase CBM wellbores.

\section{Application and Interpretation}

4.1. Field Application. The application characteristics of this iterative calculation are demonstrated by the examples of the Hancheng coalfield in the eastern margin of the Ordos Basin, China. These selected CBM wells create continuous production after their completion and fracturing and accumulate plenty of operational data. Two-phase flows are produced from the selected CBM wells. The producing characteristics that might influence flowing performances in two-phase producing wellbores were determined upon the two-phase flow properties.

The following parameters and their assigned values were selected for the two-phase CBM wellbore and are as follows: depth of the whole wellbore, $430 \mathrm{~m}$; Langmuir pressure of CBM reservoirs, $3.50 \mathrm{MPa}$; outside diameter of the tubing, 2.875 (2 7/8) in.; inside diameter of the casing, $7.0 \mathrm{in}$.; specific gravity of the CBM column, 0.58 ; viscosity of the CBM column, $1.70 \times 10^{-2} \mathrm{mPa} \cdot \mathrm{s}$; flowing viscosity of the water column, $7.85 \times 10^{-4} \mathrm{~Pa} \cdot \mathrm{s}$; and density of the water column, $1015 \mathrm{~kg} / \mathrm{m}^{3}$.

As is known, the measured parameters that might influence flowing performance are furnished for the proposed design method. The above operational parameters measured and independent variables are selected for CBM wellbores producing water and presented in Table 1 . These independent variables are given in order to illustrate the calculation of the design objective function for the flowing performance of two-phase flows along the annulus between the tubing and casing.

4.2. Results and Interpretations. Evaluating the accuracy of this developed modern approach is made possible with the help of measured parameters and variables from the selected CBM wellbores. Fractional error of system designing, $E$, fluctuates regularly between $-5 \%$ and $5 \%$ for the unconventional gas fields. Predicted variables of flowing performance and the percent error between the measured and predicted total pressures in the Average Pressure and Temperature methodology, Cullender and Smith methodology, and proposed methodology are shown in Table 2. The maximum relative errors in the three methodologies are determined to be $-11.14 \%,-10.34 \%$, and $-3.75 \%$, respectively. Furthermore, the average relative errors are predicted to be $2.94 \%, 2.87 \%$, and $1.13 \%$, respectively. And thus, the proposed design methodology can reduce the average relative errors by $1.81 \%$ and $1.74 \%$, respectively.

The fractional errors of system designing predicted by Average Pressure and Temperature methodology, as shown in Table 2, were calculated to be $-11.14 \%$ and $4.24 \%$. The computation of flowing pressures involved the variation in the $Z$-factor, but it assumed the entire wellbore to be at an average pressure and temperature. And this methodology does not perform well for most low gas/liquid ratios and high-pressure and high-temperature CBM wells. The fractional errors of system designing determined by the Cullender and Smith methodology were evaluated to be $-10.34 \%$ and $4.82 \%$. The computation of flowing pressures involved both variations in temperature and gas compressibility factor as a function of depth, but this methodology is developed for dry-gas wells in roughturbulent flow with an absolute roughness. The fractional errors of system designing predicted by the proposed methodology were calculated to be $-3.75 \%$ and $1.05 \%$. Therefore, the present design methodology for CBM wells mainly applied the previous procedures in oil and gas fields and the available approaches cannot provide the desired accuracy of the flowing pressures and the pertinent analysis of dynamic performance in CBM wellbores producing water.

Deviations of predicted and measured flowing pressures of CBM and the water column in two-phase wellbores are given in Figure 2. The predicted pressures accord well with the measured ones. The flowing pressures of the CBM column and the CBM and water column in the producing wellbores are both approximated with remarkable accuracy by the predicted pressures. The statistical data of CBM and water column pressure demonstrate an overall accuracy of $5.34 \%$. The computation of CBM column pressures involves both a compressibility factor with depth increments and a friction factor with the Reynolds number along the annulus between the tubing and casing. Moreover, CBM and water column pressures and flowing pressures in the bottom hole are determined by computing a liquid holdup and kinetic energy term with flow rate increments, compressibility factor with depth increments, and friction factor with a two-phase Reynolds number in two-phase CBM wellbores. The relationships developed match the CBM reservoir behavior and wellbore conditions along the annulus and give the desired results.

Figure 3 describes the variation of flowing pressures with pumping time in two-phase producing wellbores. The flowing pressures are mainly composed of the CBM column pressure, $\Delta p_{c} ; \mathrm{CBM}$ and water column pressure, $\Delta p_{\mathrm{t}}$; and flowing pressure in the bottom hole, $p_{\mathrm{bf}}$. And the flowing pressures 
TABLE 1: Measured parameters and independent variables for the CBM producing process.

\begin{tabular}{|c|c|c|c|c|c|c|c|}
\hline Well point & $\begin{array}{c}\text { Dynamic } \\
\text { water level } \\
h_{c}(\mathrm{~m})\end{array}$ & $\begin{array}{l}\text { CBM flow rate } \\
q_{\mathrm{sc}}\left(\mathrm{m}^{3} / \mathrm{d}\right)\end{array}$ & $\begin{array}{c}\text { Water flow rate } \\
q_{\mathrm{w}}\left(\mathrm{m}^{3} / \mathrm{d}\right)\end{array}$ & $\begin{array}{c}\text { Well head } \\
\text { pressure } \\
p_{\mathrm{hf}}(\mathrm{MPa})\end{array}$ & $\begin{array}{c}\text { Flowing pressure on a } \\
\text { dynamic level } \\
p_{\text {tcf }}(\mathrm{MPa})\end{array}$ & $\begin{array}{c}\text { Measured pressure in } \\
\text { the bottom hole } \\
p_{\mathrm{bf}}(\mathrm{MPa})\end{array}$ & $\begin{array}{c}\text { Well head } \\
\text { temperature } \\
T_{\mathrm{h}}(\mathrm{K})\end{array}$ \\
\hline 1 & 160 & 6721 & 35.7 & 0.451 & 0.455 & 1.328 & 285.79 \\
\hline 2 & 338 & 6063 & 40.8 & 1.106 & 1.137 & 1.482 & 286.15 \\
\hline 3 & 389 & 5796 & 37.6 & 1.313 & 1.372 & 1.579 & 286.18 \\
\hline 4 & 396 & 5415 & 35.5 & 1.458 & 1.516 & 1.707 & 286.20 \\
\hline 5 & 402 & 4162 & 33.8 & 1.124 & 1.155 & 1.363 & 286.21 \\
\hline 6 & 418 & 4058 & 28.3 & 1.742 & 1.801 & 1.908 & 287.29 \\
\hline 7 & 426 & 3925 & 32.7 & 1.785 & 1.844 & 1.919 & 288.05 \\
\hline 8 & 431 & 3611 & 23.5 & 2.002 & 2.073 & 2.141 & 288.67 \\
\hline 9 & 436 & 3694 & 22.4 & 1.909 & 1.968 & 2.016 & 289.77 \\
\hline 10 & 439 & 3327 & 18.2 & 2.157 & 2.216 & 2.252 & 289.83 \\
\hline
\end{tabular}

The selected CBM wells have been investigated for many years in the Hancheng coalfield.

TABLE 2: Predicted variables of flowing pressure and error in the approaches due to the relationships developed in two-phase CBM wellbores.

\begin{tabular}{|c|c|c|c|c|c|c|c|c|}
\hline \multirow{2}{*}{ Well point } & \multicolumn{2}{|c|}{$\begin{array}{l}\text { Average Pressure and } \\
\text { Temperature method }\end{array}$} & \multicolumn{2}{|c|}{$\begin{array}{l}\text { Cullender \& Smith } \\
\text { methodology }\end{array}$} & \multicolumn{4}{|c|}{ The proposed methodology } \\
\hline & $\begin{array}{l}\text { Predicted } p_{\mathrm{bf}} \\
\quad(\mathrm{MPa})\end{array}$ & $\begin{array}{l}\text { Error } E \\
\quad(\%)\end{array}$ & $\begin{array}{l}\text { Predicted } p_{\mathrm{bf}} \\
\quad(\mathrm{MPa})\end{array}$ & $\begin{array}{c}\text { Error } E \\
(\%)\end{array}$ & $\begin{array}{c}\text { CBM column } \\
\text { pressure } \Delta p_{\mathrm{c}}(\mathrm{MPa})\end{array}$ & $\begin{array}{l}\mathrm{CBM} \text { and water column } \\
\text { pressure } \Delta p_{\mathrm{t}}\left(10^{4} \mathrm{~Pa}\right)\end{array}$ & $\begin{array}{l}\text { Predicted } p_{\mathrm{bf}} \\
\quad(\mathrm{MPa})\end{array}$ & $\begin{array}{c}\text { Error } E \\
\quad(\%)\end{array}$ \\
\hline 1 & 1.4759 & -11.14 & 1.4657 & -10.34 & 0.0052 & 0.9216 & 1.3778 & -3.75 \\
\hline 2 & 1.5397 & -3.90 & 1.5472 & -4.40 & 0.0284 & 0.3928 & 1.5272 & -3.05 \\
\hline 3 & 1.6122 & -2.11 & 1.6021 & -1.46 & 0.0643 & 0.2220 & 1.5993 & -1.29 \\
\hline 4 & 1.7433 & -2.13 & 1.7369 & -1.75 & 0.0639 & 0.2028 & 1.7247 & -1.03 \\
\hline 5 & 1.3052 & 4.24 & 1.2973 & 4.82 & 0.0321 & 0.1926 & 1.3487 & 1.05 \\
\hline 6 & 1.8865 & 1.13 & 1.8726 & 1.86 & 0.0547 & 0.1061 & 1.9028 & 0.27 \\
\hline 7 & 1.9321 & -0.69 & 1.9107 & 0.43 & 0.0575 & 0.07770 & 1.9202 & -0.07 \\
\hline 8 & 2.1137 & 1.28 & 2.1178 & 1.08 & 0.0641 & 0.06662 & 2.1327 & 0.39 \\
\hline 9 & 2.0462 & -1.48 & 2.0379 & -1.08 & 0.0616 & 0.04686 & 2.0175 & -0.06 \\
\hline 10 & 2.2793 & -1.21 & 2.2838 & -1.41 & 0.0697 & 0.03461 & 2.2613 & -0.42 \\
\hline
\end{tabular}

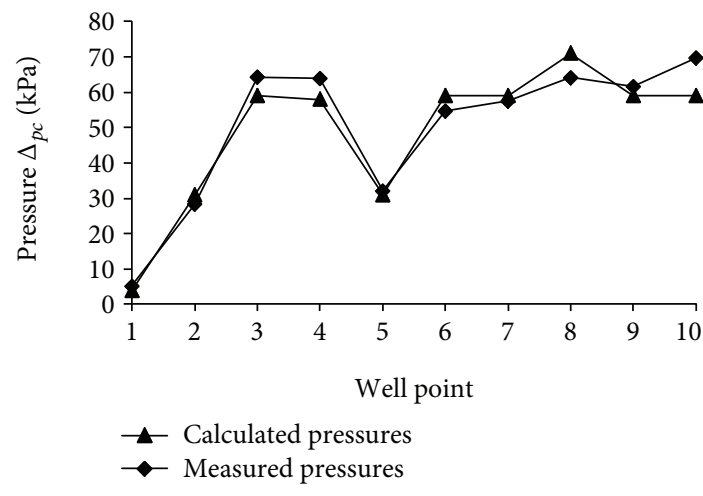

(a) CBM column pressures

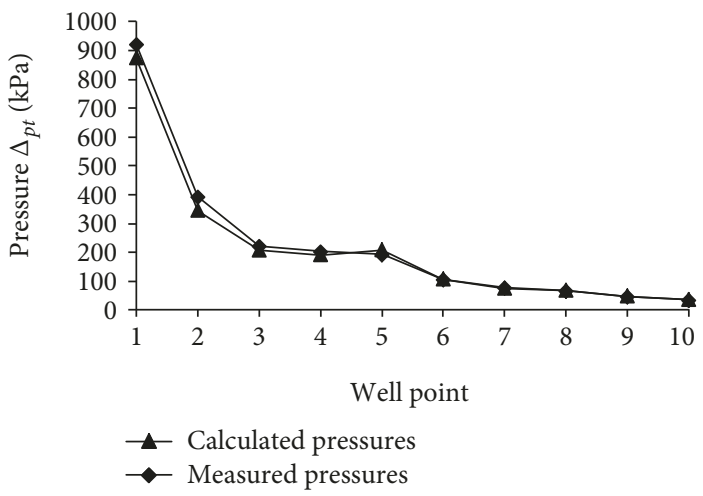

(b) CBM and water column pressures

FIGURE 2: Comparison of predicted and measured flowing pressures of CBM and the water column.

along the annulus can fully reflect dynamic flowing performance during the pumping production due to their combined action of the dynamic water level, CBM flow rate, and water flow rate.
Figure 4 is a plot of the flowing pressure function as it varies with the dynamic water level and flow rate for the different phases of CBM producing process. The parameter that is a function of the flowing pressure ratio has been 


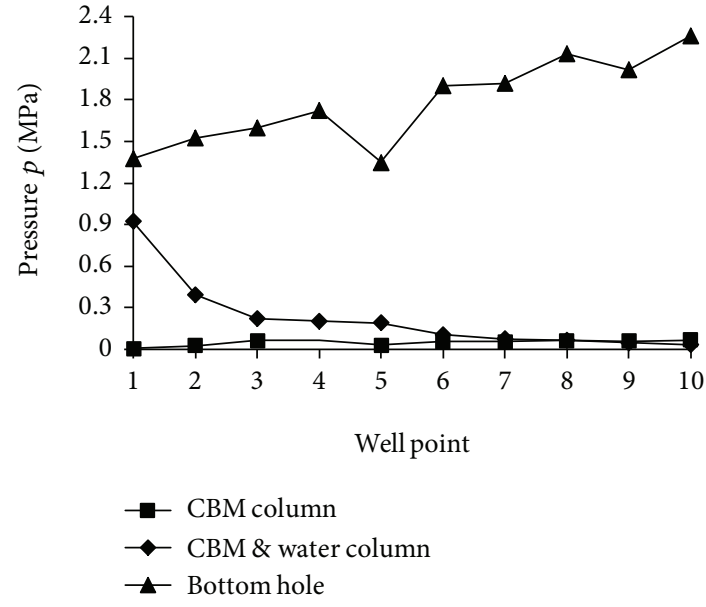

FIGURE 3: The variation of flowing pressures with pumping time in two-phase producing wellbores.

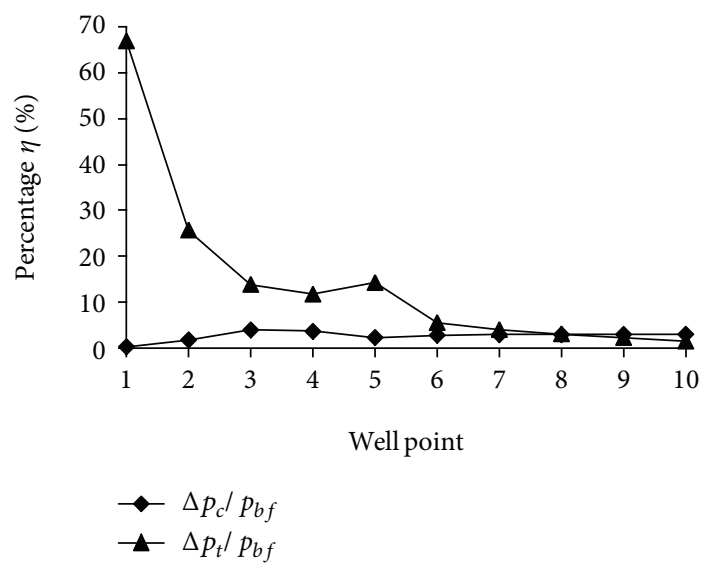

FIGURE 4: The ratios of flowing pressures in two-phase producing wellbores.

introduced. It can be seen from the figure that the ratios of $\mathrm{CBM}$ and water column pressure to flowing pressure in the bottom hole are relatively high in CBM wellbores producing water. And thus, the effect of CBM and water column pressures cannot be neglected while predicting and analyzing flowing performance. The average ratios of CBM column pressure and $\mathrm{CBM}$ and water column pressure to flowing pressure in the bottom hole are predicted to be $2.7 \%$ and $15.0 \%$, respectively. Moreover, the effect of CBM and water column pressures is more obvious than that of CBM column pressures along the annulus between the tubing and casing. And the ratios of CBM and water column pressure to flowing pressure in the bottom hole decline rapidly with the increase of the dynamic water level. The pressure ratios decline from $66.9 \%$ to $25.7 \%$ and then to $13.9 \%$ while the dynamic water levels decrease from $160 \mathrm{~m}$ to $389 \mathrm{~m}$ in two-phase CBM wellbores.

Figure 5 is given to illustrate the relationships between the CBM flow rate and the CBM and water column pressure for different phases of CBM producing process. The CBM flow rate can be improved with the help of increase of CBM

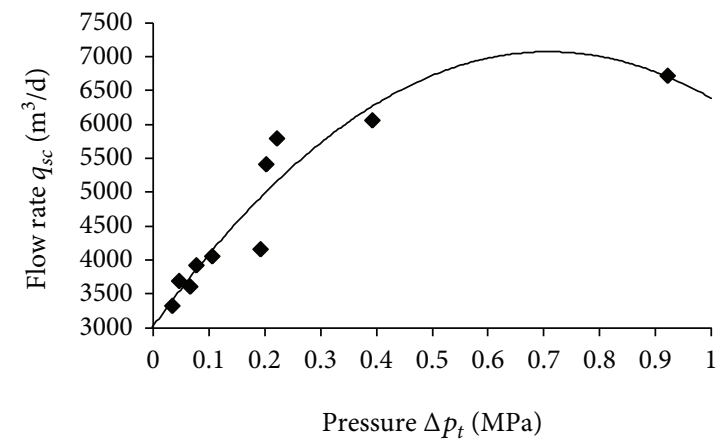

Figure 5: Effect of CBM and water column pressure on CBM production in two-phase producing wellbores.

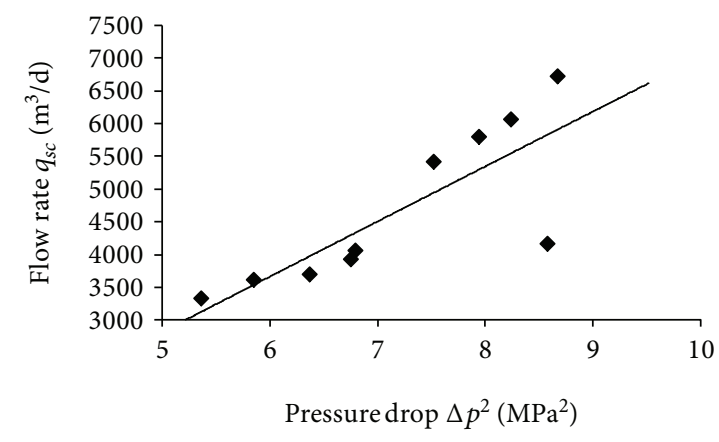

FIGURE 6: Effect of pressure drop on CBM production in two-phase producing wellbores.

and water column pressure for two-phase producing wellbores. It can be seen from the figure that CBM flow rates increase from $3327 \mathrm{~m}^{3} / \mathrm{d}$ to $6721 \mathrm{~m}^{3} / \mathrm{d}$ while CBM and water column pressures increase from $34.6 \mathrm{kPa}$ to $922 \mathrm{kPa}$.

Figure 6 shows the variation of CBM production vs. pressure drop in two-phase producing wellbores. And the curve with the linear form represents the CBM flow rate as a function of pressure drop between Langmuir pressure and flowing pressure in the bottom hole. An increased increment of pressure drop is beneficial to CBM desorption and results to an increased CBM production. And it provides an effective measure to improve the CBM flow rate in the wellbores producing water. $\mathrm{CBM}$ column pressures and $\mathrm{CBM}$ and water column pressures enhance the imbalance of flowing pressures in the bottom hole of the producing wellbores. CBM production is variable in a large scale due to the flowing pressure drop for the different phases of the CBM producing process. It can be seen from the figure that flowing pressures in the bottom hole decrease from $2.141 \mathrm{MPa}$ to $1.328 \mathrm{MPa}$ while the increments of pressure drop increase from $5.849 \mathrm{MPa}^{2}$ to $8.669 \mathrm{MPa}^{2}$ and CBM flow rates enhance from $3611 \mathrm{~m}^{3} / \mathrm{d}$ to $5906 \mathrm{~m}^{3} / \mathrm{d}$ in two-phase producing wellbores.

Figure 7 is given to illustrate the relationships between water flow rate and CBM and water column pressure for different phases of the CBM producing process. The water flow rate increases due to increases in CBM and water column pressure along two-phase producing wellbores. Its variation with flowing pressures is more complex because of the 


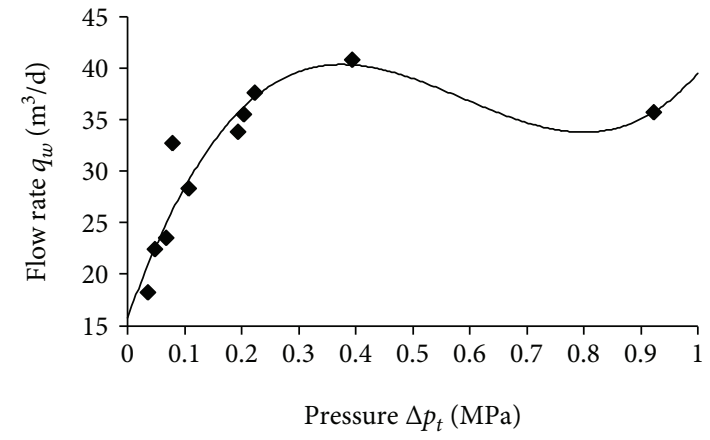

FIGURE 7: Effect of CBM and water column pressure on water production in two-phase producing wellbores.

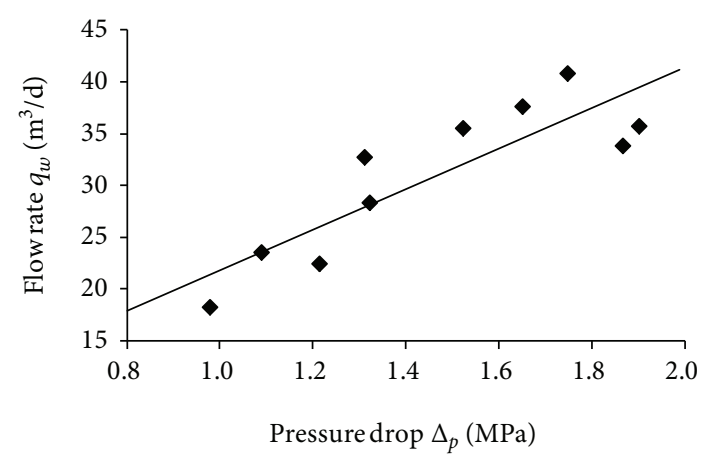

FIGURE 8: Effect of pressure drop on water production in two-phase producing wellbores.

CBM well conditions and the behavior of coal reservoirs. The coal reservoirs produce less and less water while the CBM flow rate enhances gradually during the depletion. And the producing CBM wellbores exhibit two-phase flowing performances. It can be seen from the figure that water flow rates increase from $18.2 \mathrm{~m}^{3} / \mathrm{d}$ to $40.8 \mathrm{~m}^{3} / \mathrm{d}$ and then to $35.7 \mathrm{~m}^{3} / \mathrm{d}$ while $\mathrm{CBM}$ and water column pressures increase from $34.61 \mathrm{kPa}$ to $392.80 \mathrm{kPa}$ and then to $921.60 \mathrm{kPa}$.

Figure 8 describes the variation of water production vs. pressure drop in two-phase producing wellbores. And the curve represents the water flow rate as a function of pressure drop between the Langmuir pressure and flowing pressure in the bottom hole. As is apparent from the curve, water flow rate increases monotonically with the operating variables of pressure drop. The variation range of production rate changes with various pressure drops. Consequently, the falling speed of the dynamic water level can be controlled with regard to the limitations of flowing pressures. And it will satisfy the requirements of actual production of the oil/gas process. It can be seen from the figure that water flow rates increase from $23.5 \mathrm{~m}^{3} / \mathrm{d}$ to $28.3 \mathrm{~m}^{3} / \mathrm{d}$ and then to $39.52 \mathrm{~m}^{3} / \mathrm{d}$ while the increments of pressure drop increase from $1.089 \mathrm{MPa}$ to $1.322 \mathrm{MPa}$ and then to $1.902 \mathrm{MPa}$.

\section{Conclusions}

These flowing pressures can be predicted by taking the effect of entrained CBM and water on gravitational gradients into account. And the methodology is validated against full-scale measured data in coalfields. The predicted pressures of the CBM column and CBM and water column accord well with the measured ones with an overall relative error of $1.5 \%$ upon the proposed algorithm. And it could satisfy the accuracy requirements in the engineering design. CBM column pressure, $\mathrm{CBM}$ and water column pressure, and flowing pressure in the bottom hole fully reflect dynamic flowing performance due to their combined action of the dynamic water level, CBM flow rate, and water flow rate. The average ratios of $\mathrm{CBM}$ column pressure and CBM and water column pressure to flowing pressure in the bottom hole are predicted to be $2.7 \%$ and $15.0 \%$, respectively. CBM column pressures and $\mathrm{CBM}$ and water column pressures enhance the imbalance of flowing pressures in the bottom hole of the producing wellbores. The increases of CBM and water column pressure from $34.6 \mathrm{kPa}$ to $922 \mathrm{kPa}$ and the decreases of pressure in the bottom hole from $2.252 \mathrm{MPa}$ to $1.328 \mathrm{MPa}$ result in the increases of the CBM flow rate from $3327 \mathrm{~m}^{3} / \mathrm{d}$ to $6721 \mathrm{~m}^{3} / \mathrm{d}$.

The result of this work is that the methodology involved a numerical integration technique to predict and analyze the flowing pressures of a two-phase CBM and water column. This makes it possible to identify CBM reservoir behavior and wellbore conditions along the annulus between the tubing and casing. Moreover, the proposed methodology leads to the results of forecasting the flowing performance of $\mathrm{CBM}$ and water flow and solving the forthcoming problems in two-phase producing wellbores.

\section{Data Availability}

The data used to support the findings of this study are included within the article (Tables 1 and 2).

\section{Conflicts of Interest}

The authors declare that they have no conflicts of interest.

\section{Acknowledgments}

This work was financially supported by the National Science and Technology Major Project of the Ministry of Science and Technology of China under Award No. 2016ZX05065-001, Higher Education Research and Development Project of Shandong Province under Award No. J17KA033, and Key Research Project of Shandong Province under Award No. GG201809190050.

\section{References}

[1] R. Mitchell, "Casing design with flowing fluids," SPE Drilling \& Completion, vol. 26, no. 3, pp. 432-435, 2011.

[2] S. Mohammed and G. S. Enty, "Analysis of gas production data using flowing material balance method," SPE Nigeria Annual International Conference and Exhibition, 2013, Lagos City, Nigeria, August 2013, 2013.

[3] O. Bello and T. Asafa, "A functional networks softsensor for flowing bottomhole pressures and temperatures in multiphase production wells," in SPE Intelligent Energy Conference \& Exhibition, Utrecht City, The Netherlands, April 2014. 
[4] S. A. Osman, M. A. Ayoub, and M. A. Aggour, "An artificial neural network model for predicting bottomhole flowing pressure in vertical multiphase flow," SPE Middle East Oil and Gas Show and Conference, 2005, Kingdom of Bahrain, March 2005, 2005.

[5] T. A. Obeida and Y. H. Mosallam, "Calculation of flowing bottom-hole pressure constraint based on bubble point pressure versus depth relationship," EUROPEC/EAGE Conference and Exhibition, 2007, London City, UK, June 2007, 2007.

[6] C. M. Rendeiro and C. M. Kelso, "An investigation to improve the accuracy of calculating bottomhole pressures in flowing gas wells producing liquids," in Permian Basin Oil and Gas Recovery Conference, Midland City, TX, USA, March 1988.

[7] J. D. Guzman, J. A. Arevalo, and O. Espinola, "Reserves evaluation of dry gas reservoirs through flowing pressure material balance method," in SPE Energy Resources Conference, Port of Spain City, Trinidad and Tobago, June 2014.

[8] J. W. Peffer, M. A. Miller, and A. D. Hill, "An improved method for calculating bottomhole pressures in flowing gas wells with liquid present," SPE Production Engineering, vol. 3, no. 4, pp. 643-655, 1988.

[9] M. Mohammadpoor, K. Shahbazi, and A. R. Q. Firouz, “A new methodology for prediction of bottomhole flowing pressure in vertical multiphase flow in Iranian oil fields using artificial neural networks (ANNs)," in SPE Latin American and Caribbean Petroleum Engineering Conference, Lima City, Peru, December 2010.

[10] E.-S. A. Osman and M. A. Aggour, "Artificial neural network model for accurate prediction of pressure drop in horizontal and near-horizontal-multiphase flow," Petroleum Science and Technology, vol. 20, no. 1, pp. 1-15, 2002.

[11] X. F. Liu, "Prediction of flowing bottomhole pressures for twophase coalbed methane wells," Acta Geologica Sinica, vol. 87, no. 5, pp. 1412-1420, 2013.

[12] Y. D. Yao and J. L. Ge, "Characteristics of non-Darcy flow in low-permeability reservoirs," Petroleum Science, vol. 8, no. 1, pp. 55-62, 2011.

[13] C. R. Clarkson, R. M. Bustin, and J. P. Seidle, "Production-data analysis of single-phase (gas) coalbed-methane wells," SPE Reservoir Evaluation \& Engineering, vol. 10, no. 3, pp. 312331, 2007.

[14] X. F. Liu, C. H. Liu, and Y. G. Qi, "Operating performance of sucker rod pump for the pumping system in coalbed methane wells," Journal of Mechanical Engineering, vol. 53, no. 8, pp. 195-200, 2017.

[15] A. H. Vicki and S. S. Paul, A Guide to Coalbed Methane Operations, Gas Research Institute, Alabama, Birmingham, 2002.

[16] X. F. Liu, Y. G. Qi, A. M. Hu, P. H. Zhao, and C. H. Liu, "Inflow performance relationship in two-phase CBM wells," Journal of China University of Mining \& Technology, vol. 40, no. 4, pp. 561-591, 2011.

[17] K. E. Okuszko, B. W. Gault, and L. Mattar, "Production decline performance of CBM wells," Journal of Canadian Petroleum Technology, vol. 47, no. 7, pp. 913-917, 2008.

[18] I. Sugiarto, S. Mazumder, R. Wittemeier, and V. Sharma, "Inflow performance relationship correlation of 2 phase CBM reservoir," in SPE/IATMI Asia Pacific Oil \& Gas Conference and Exhibition, Nusa Dua City, Indonesia, October 2015.

[19] L. Mattar and R. McNeil, "The "flowing" gas material balance," Journal of Canadian Petroleum Technology, vol. 37, no. 2, pp. 287-291, 1998.
[20] S. Mohammed, O. Jeje, and M. Louis, "Advanced gas material balance in simplified format," Journal of Canadian Petroleum Technology, vol. 50, no. 1, pp. 90-98, 2011.

[21] C. A. Mora and R. A. Wattenbarger, "Analysis and verification of dual porosity and CBM shape factors," Journal of Canadian Petroleum Technology, vol. 48, no. 2, pp. 17-21, 2009.

[22] R. P. Sutton, "An accurate method for determining oil PVT properties using the standing-Katz gas Z-factor chart," SPE Reservoir Evaluation \& Engineering, vol. 11, no. 2, pp. 246266, 2008.

[23] L. L. Langelandsvik, W. Postvoll, P. Svendsen, and J. M. Overli, "An evaluation of the friction factor formula based on operational data," PSIG Annual Meeting, 2005, San Antonio City, TX, USA, November 2005, 2005.

[24] M. U. Yalniz and E. Ozkan, "A generalized friction factor correlation to compute pressure drop in horizontal wells," $S P E$ Production \& Facilities, vol. 16, no. 4, pp. 232-239, 2001.

[25] S. Tang, C. X. Liu, and Y. H. Dong, "Multiphase flow model developed for simulating gas hydrate transport in horizontal pipe," Applied Mathematics and Mechanics, vol. 37, no. 9, pp. 1193-1202, 2016.

[26] A. H. White and F. T. Smith, "Wall shape effects on multiphase flow in channels," Theoretical and Computational Fluid Dynamics, vol. 26, no. 1-4, pp. 339-360, 2012.

[27] J. Borowsky and T. Wei, "Simultaneous velocimetry/accelerometry measurements in a turbulent two-phase pipe flow," Experiments in Fluids, vol. 41, no. 1, pp. 13-20, 2006.

[28] W. G. Sim, B. M. Bae, and N. W. Mureithi, "An experimental study on characteristics of two-phase flows in vertical pipe," Journal of Mechanical Science and Technology, vol. 24, no. 10, pp. 1981-1988, 2010.

[29] E. A. Boltenko, "Determination of the density and flow rate of the two-phase mixture under steady and emergency conditions," Thermal Engineering, vol. 60, no. 3, pp. 195-201, 2013.

[30] S. D. Lyubarskii and A. S. Ivanov, "Motion of a compressed two-phase medium of bulk density upon sudden expansion," Combustion, Explosion and Shock Waves, vol. 25, no. 3, pp. 335-337, 1989.

[31] M. Bazmi, S. H. Hashemabadi, and M. Bayat, "Extrudate trilobe catalysts and loading effects on pressure drop and dynamic liquid holdup in porous media of trickle bed reactors," Transport in Porous Media, vol. 99, no. 3, pp. 535-553, 2013.

[32] J. Rajarajan, D. Pollard, A. P. Ison, and P. A. Shamlou, "Gas holdup and liquid velocity in airlift bioreactors containing viscous Newtonian liquids," Bioprocess Engineering, vol. 14, no. 6, pp. 311-315, 1996.

[33] M. E. Shippen and S. L. Scott, "A neural network model for prediction of liquid holdup in two-phase horizontal flow," SPE Production \& Facilities, vol. 19, no. 2, pp. 67-76, 2004. 

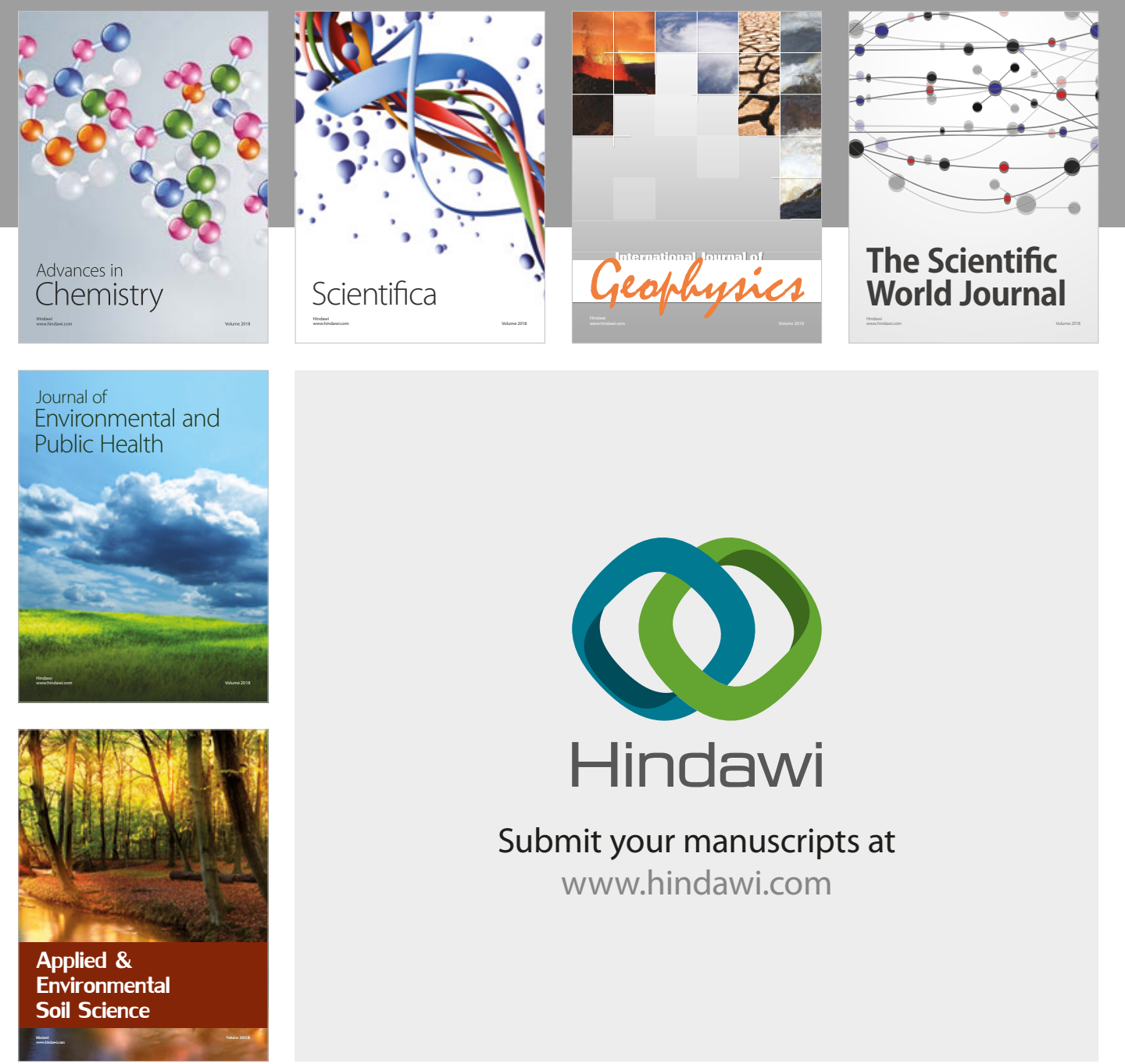

The Scientific

\section{World Journal}
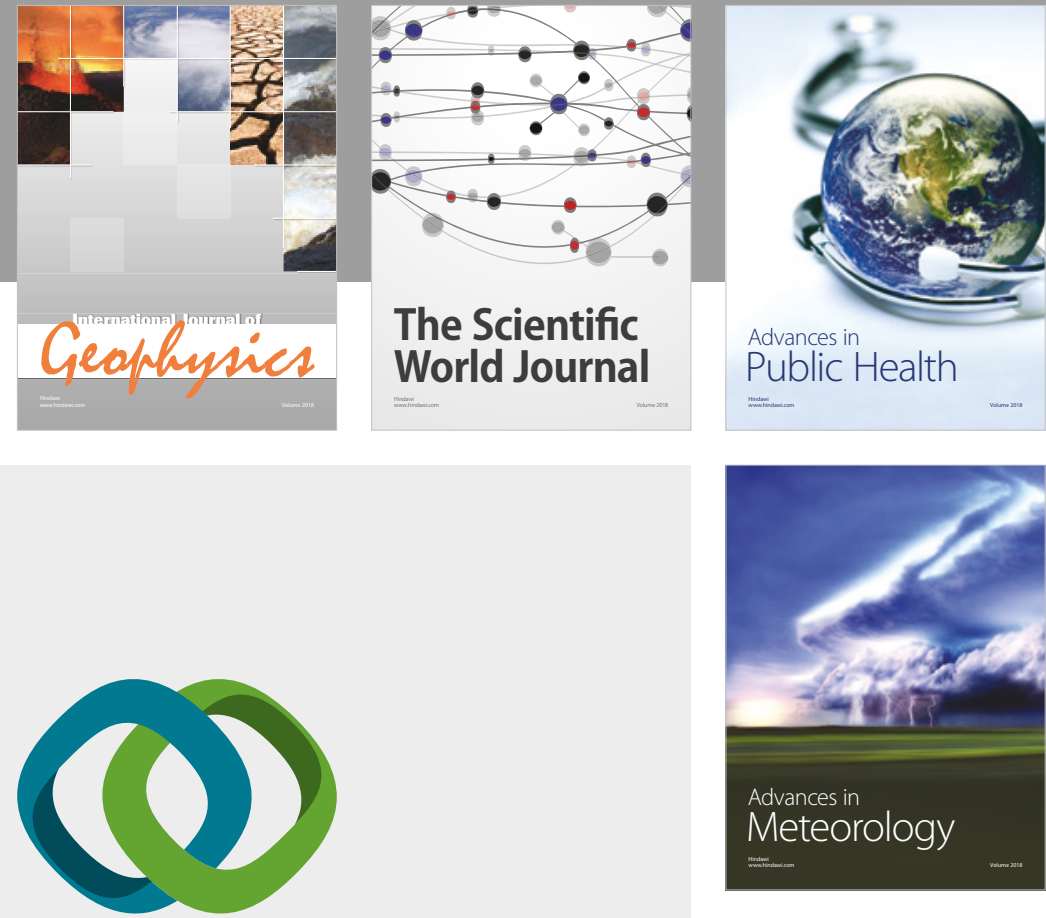

Advan

Public Health

\section{Hindawi}

Submit your manuscripts at

www.hindawi.com
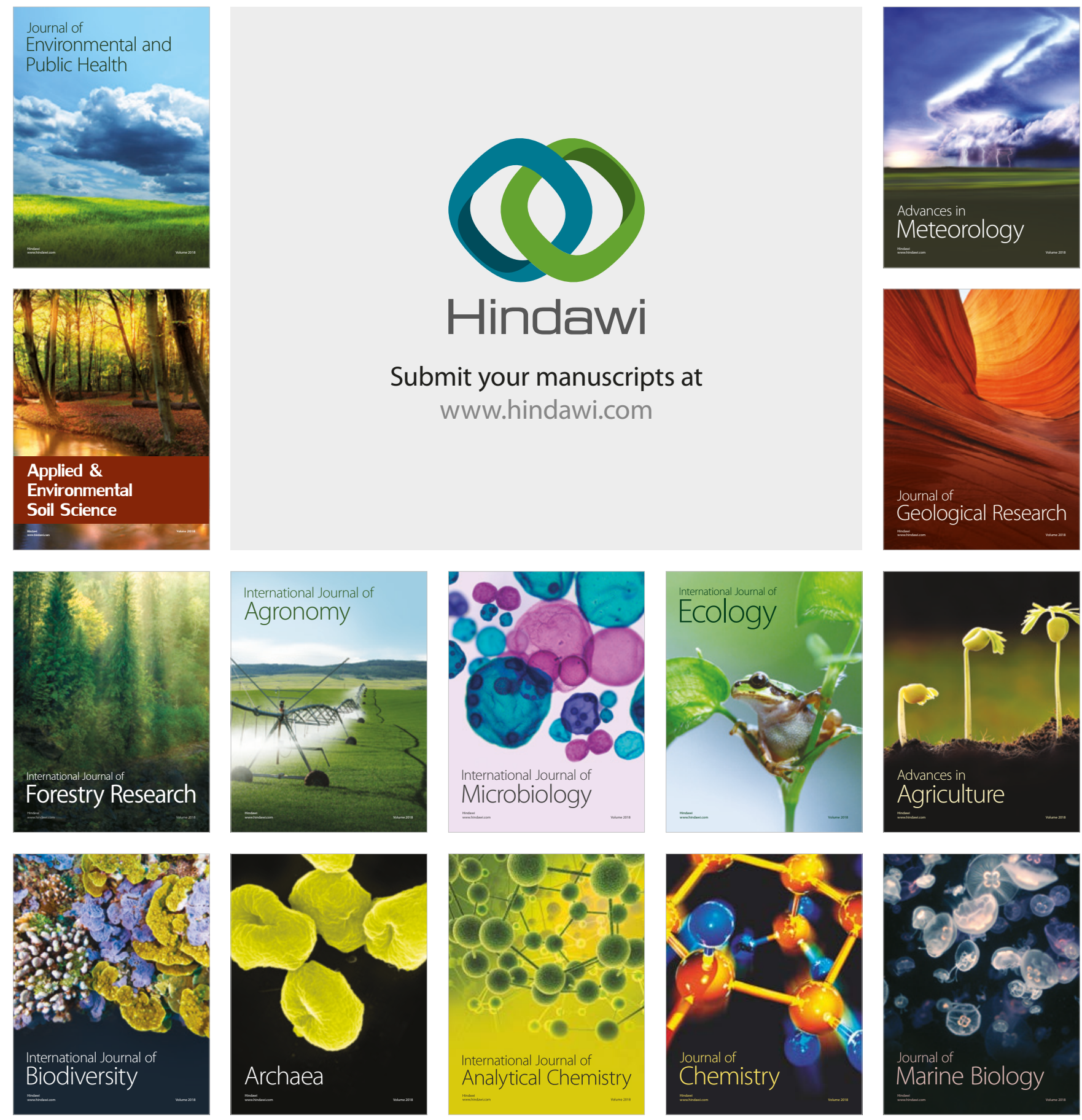